\title{
SISTEM INFORMASI PENDAFTARAN MAHASISWA BARU BERBASIS WEB PADA POLITEKNIK SAINS \& TEKNOLOGI WIRATAMA MALUKU UTARA
}

\author{
INFORMATION SYSTEM FOR REGISTRATION NEW STUDENTS BASED ON \\ WEBSITE IN POLITEKNIK SAINS \& TECHNOLOGY WIRATAMA MALUKU UTARA
}

\author{
Sugeng Priyanto ${ }^{1}$, Hairil Kurniadi Siradjuddin ${ }^{2}$ \\ ${ }^{1}$ Prodi Manajemen Informatika \\ Politeknik Sains dan Teknologi Wiratama Maluku Utara \\ ${ }^{2}$ Fakultas Teknik, Prodi Teknik Informatika \\ Universitas Khairun Ternate \\ sugengpriyanto842@gmail.com
}

\begin{abstract}
Abstrak
Politeknik Sains \& Teknologi Wiratama Maluku Utara merupakan salah satu instansi yang bergerak di bidang pendidikan yang menerapkan teknologi informasi dalam membantu kegiatan operasionalnya, sistem pelayanan pendaftaran dan informasi penerimaan mahasiswa baru masih bersifat konvensional dimana calon mahasiswa baru tersebut harus datang ke kampus tersebut untuk melakukan pendaftaran, dilain sisi informasi yang lain yang berhubungan dengan pendaftaran sampai kelulusan calon mahasiswa tersebut harus datang untuk menanyakan lansung ke panitia dan melihatnya dipapan pengumuman sehingga dianggap kurang efektif. Dalam penelitian ini jenis data yang digunakan oleh peneliti adalah data sekunder, yaitu jenis data yang di dapat dari dokumen yang dijadikan sebagai referensi. Sumber data yang di dapat oleh peneliti yaitu pada objek penelitian di Politeknik Sains \& Teknologi Wiratama Maluku Utara. Sistem ini dapat mempermudah admin dalam pengolahan dan pengelolaan data calon mahasiswa baru. Serta dapat mempercepat informasi pendaftaran dan pengumuman hasil calon mahasiswa baru melalui website. dan meningkatkan kinerja dan pelayanan pada Politeknik Sains \& Teknologi Wiratama Maluku Utara lebih efektif dan efisien.
\end{abstract}

\section{Kata kunci: Sistem Informasi, Mahasiswa Baru, Website}

\begin{abstract}
Politeknik Sains dan Teknologi Wiratama North Maluku is one of the agencies engaged in field of education applying information technology in assisting its operational activities, current registration service system and information of new student admission still conventional where new student candidate must come to campus to do registration, on the other side of information related to registration until graduation of candidate the student must come to inquire directly to the committee and see it in the announcement so that it is considered less effective. In this research the types of data used by researchers are secondary data, that is the types of data that can be used as documents of reference. Sources of data in the can by the researcher are on the object of research at Politeknik Sains dan Teknologi Wiratama North Maluku. This system can facilitate admin in the processing and management of new student data. And can speed up the registration information and the announcement of the results of prospective new students through the website. and improving performance and
\end{abstract}


service at the Polytechnic University of Science Technology \& Wiratama North Maluku is more effective and efficient.

\section{Keywords: Information Systems, New Student, Website}

\section{PENDAHULUAN}

Penerapan fungsi teknologi informasi membuat institusi - intitusi harus meningkatkan fungsi teknologi informasi, salah satunya yang ada pada sistem pelayanan yang ada pada institusi dalam menjalankan aktivitasnya salah satunya yang ada pada institusi pendidikan

Pelayanan merupakan suatu hal yang sangat penting dalam membantu menigkatkan efektifitas kinerja dari setiap institusi, salah satu yang ada pada institusi pendidikan dalam melakukan pelayanan pendaftaran mahasiswa baru di kampus

Calon Mahasiswa adalah siswa yang telah menyelesaikan pendidikan pada sekolah menengah atas atau sekolah menegah kejuruan untuk melanjutkan studi kuliahnya pada perguruan tinggi yang diinginkan dan melakukan pendaftaran pada perguruan tinggi tersebut, dalam melakukan pendaftaran calon mahasiswa membutuhakan suatu pelayanan yang memudahkan calon mahasiswa memperoleh informasi secara cepat

Politeknik Sains \& Teknologi Wiratama Maluku Utara merupakan salah satu instansi yang bergerak di bidang pendidikan yang menerapkan teknologi informasi dalam membantu kegiatan operasionalnya, saat ini sistem pelayanan pendaftaran dan informasi penerimaan mahasiswa baru masih bersifat konvensional dimana calon mahasiswa baru tersebut harus datang ke kampus tersebut untuk melakukan pendaftaran, dilain sisi informasi yang lain yang berhubungan dengan pendaftaran sampai kelulusan calon mahasiswa tersebut harus datang untuk menanyakan lansung ke panitia dan melihatnya dipapan pengumuman sehingga dianggap kurang efektif

Berdasarkan uraian tersebut maka dibutuhkan suatu sistem yang berbasis web, web digunakan agar calon mahasiswa dapatmelakukan pendaftaran dan melihat informasi mengenai pendaftaran dimana saja pada sistem

\section{Rumusan Masalah}

Bagaimana merancang sistem informasi pendaftaran calon mahasiswa baru pada Politeknik Sains \& Teknologi Wiratama Maluku Utara, agar dapat memudahkan calon mahasiswa dalam mengakses informasi dan melakukan pendaftaran pada sistem,dandapat memudahkan panitia dalam mengelola data pendaftaran secara cepat dan efisien, sehingga dapat meningkatkan kinerja dan pelayanan pada Politeknik Sains \& Teknologi Wiratama Maluku Utara terutama pada pendaftaran mahasiswa baru

\section{LANDASAN TEORI}

\section{Pengertian sistem}

Konsep sistem (Darmawan dan Fauzi: 2013) konsep-konsep sistem dapat bermanfaat untuk membantu melaksanakan fungsi manajemen agar lebih efektif, peernyataan ini dapat diterapkan saat kita menjalankan sistem apa pun, baik itu sistem di departemen pendidikaan, perusahaan industri, ataupun bagian sistem informasi itu sendiri.

\section{Pengertian Sistem Informasi}

Taufiq (2013).mendefinisikan sistem informasi adalah kumpulan dari sub-sub 
sistem yang saling terintegrasi dan berkolaborasi untuk menyelesaikan masalah tertentu dengan cara mengolah data dengan alat yang namamya komputer sehingga memiliki nilai tambah dan bermanfaat bagi pengguna.

\section{Pendaftaran}

Penerimaan Peserta Didik Baru (PPDB) adalah kegiatan penerimaan dan seleksi calon peserta pendidikan dan pelatihan pada sekolah hal tersebut berkaitan dengan kemampuan dasar akademik dan minat bakat terhadap jenjang sekolah yang di tuju sebagai bentuk awal pengendalian penjaminan dan penetapan mutu pendidikan

\section{Pengertian Database}

Fathansyah (2004) mendefinisikan "Basis data terdiri atas dua kata, yaitu basis dan data.Basis kurang lebih dapat diartikan sebagai markaas atau gudang.Sedangkan data adalah representasi fakta dunia nyata mewakili suatu objek seperti manusia (pegawai, siswa, pembeli, pelanggan), barang, hewan, peristiwa, konsep, keadaan dan sebagainya, yang direkam dalam bentuk angka, huruf, simbol.teks, gambar, bunyi, atau kombinasinya".

\section{Pengertian HTML}

HTML adalah bahasa markah yang digunakan untuk menyusun halaman web.Kodenya berupa kumpulan tag-tag, dengan setiap ditandai dengan $<$ dan diakhiri dengan $>$. Tag bisa mewakili elemen di halaman web, misalnya <img> menyatakan elemen gambar serta pasangan $\quad<\mathrm{a}>$ dan $</ a>$ mmenyatakanhyperlink (Kadir dan Triwahyuni, 2013).

\section{Pengertian $\boldsymbol{P H P}$}

Menurut Saputra (2011) PHP merupakan suatu bahasa pemograman yang difungsikan untuk membangun suatu web dinamis.PHP ini bersifat open source sehingga dapat dipakai secara cuma-cuma dan mampu lintas platform, yaitu dapat berjalan pada sistem operasi windows maupun linux.

\section{Pengertian Diagram Flow Data (DFD)}

Wijaya (2007) mendefinisikan DFD (Data Flow Diagram) adalah gambaran grafis yang memperlihatkan aliran data dari sumbernya dalam objek kemudian melewati suatu proses yang mentransformasikan ke tujuan yang lain, yang ada pada objek lain

\section{METODE PENELITIAN}

Untuk meneliti proses pendaftaran calon mahasiwa baru pada Politeknik Sains \& Teknologi Wiratama Maluku Utara jenis data yang digunakan oleh peneliti adalah data sekunder, yaitu jenis data yang di dapat dari dokumen yang dijadikan sebagai referensi. Sumber data yang di dapat oleh peneliti yaitu pada objek penelitian di Politeknik Sains \& Teknologi Wiratama Maluku Utara.

\section{Metode Pengembangan Sistem}

Metode Waterfall merupakan metode yang sering digunakan oleh penganalisa sistem pada umumnya.Inti dari metode waterfall adalah pengerjaan dari suatu sistem dilakukan secara berurutan atau secara linear. Jadi jika langkah ke-1 belum dikerjakan , maka langkah ke-2 tidak dapat dikerjakan. Jika langkah ke-2 belum dikerjakan maka langkah ke-3 juga tidak dapat dikerjakan begitu juga seterusnya. Secara otomatis langkah ke-3 akan bisa dikerjakan apabila langkah ke-1 dan ke-2 
sudah selesai dalam pekerjaanya. Secara garis besar metode waterfall mempunyai langkah-langkah sebagai berikut: (Rosa,2013)

\section{Kebutuhan Fungsional}

Pada Politeknik Sains \& Teknologi Wiratama Maluku Utara membutuhkan sebuah sistem yang memberikan informasi yang sesuai dan dapat di informasikan ke calon mahasiswa baru. Adapun kebutuhan sistem yang digunakan untuk menganalisis sistem ini meliputi kebutuhan fungsiaonal di antaranya sebagai berikut :

1. Memudahkan calon mahasiswa baru dalam mendaftar di Politeknik Sains \& Teknologi Wiratama Maluku Utara.

2. Meminimalisir waktu bagi calon mahasiswa baru dan juga panitia dalam penerimaan calon mahasiswa.

3. Dengan adanya sistem ini pihak kampus dapat lebih banyak menerima calon mahasiswa baru.

\section{Kebutuhan Non-Fungsional}

Untuk kebutuhan non fungsional dalam pembuatan suatu sistem yang di rancang mempunyai kebutuhan sebagai berikut:

1. Sistem ini berbasis Website

2. Sistem dibangun dengan menggunakan bahasa pemrograman PHP dan MySql sebagai database.

3. Sistem dapat berjalan pada komputer dengan spesifikasi minimal RAM 1GB

4. Dapat diakses melalui jaringan internet.

Dalam penelitian ini dapat diuraikan spesifikasi kebutuhan perangkatperangkata dalah sebagai berikut :

Perangkat lunak yang dipakai adalah:

1. Sistem Operasi Windows7 Ultimate

2. MS Visio 2007 untuk membuat diagram flowchart
3. HTML, PHP dan Java Script sebagai script Programming

4. MySQL untuk database

5. Browser seperti Mozilla Firefox

6. Xampp 3.2.1 sebagai server

7. Notepad ++ sebagai penyunting kode

8. CSS untuk mendesain tampilan web

Perangkat keras yang dipakai adalah sebagai berikut :

1. Laptop Compaq PresarioCQ 42.

2. Processor Intel

3. RAM 2 GB

4. Hardisk $320 \mathrm{~GB}$

5. Printer canon Pixmaip 2800.

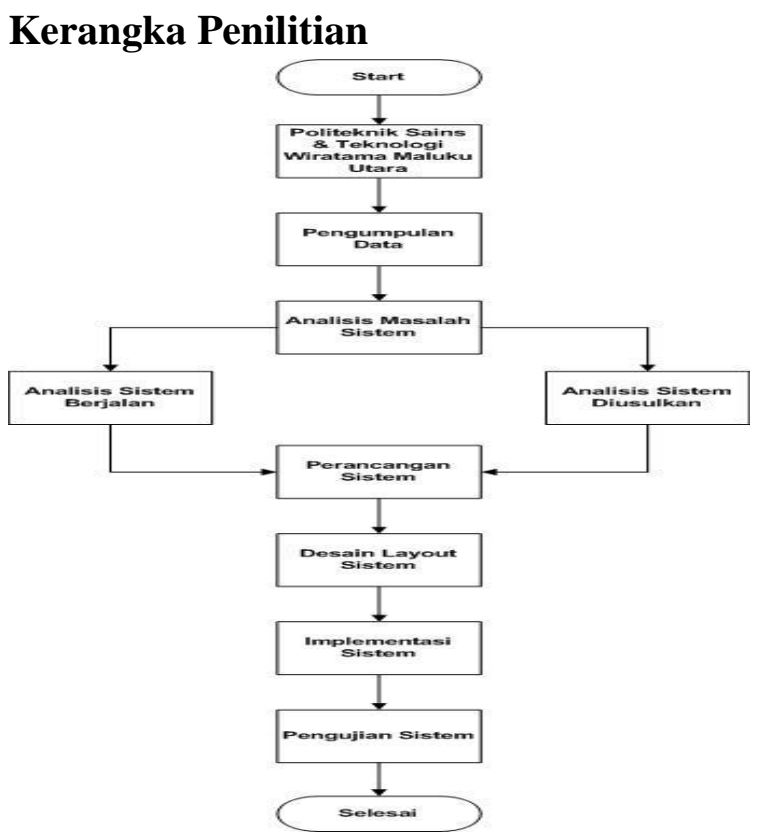

Gambar 1. Kerangka Penilitian

\section{Analisa Sistem yang Berjalan}

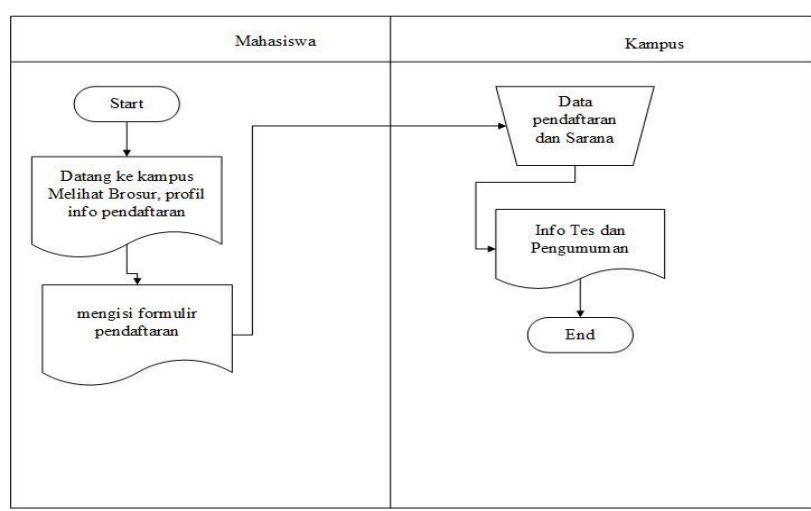

Gambar 2. Sistem yang berjalan 
Rancangan System yang Diusulkan

Berdasarkan sistem yang berjalan maka peneliti mengusulkan sistem yang baru.Berikut desain flowchart sistem yang diusulkan.

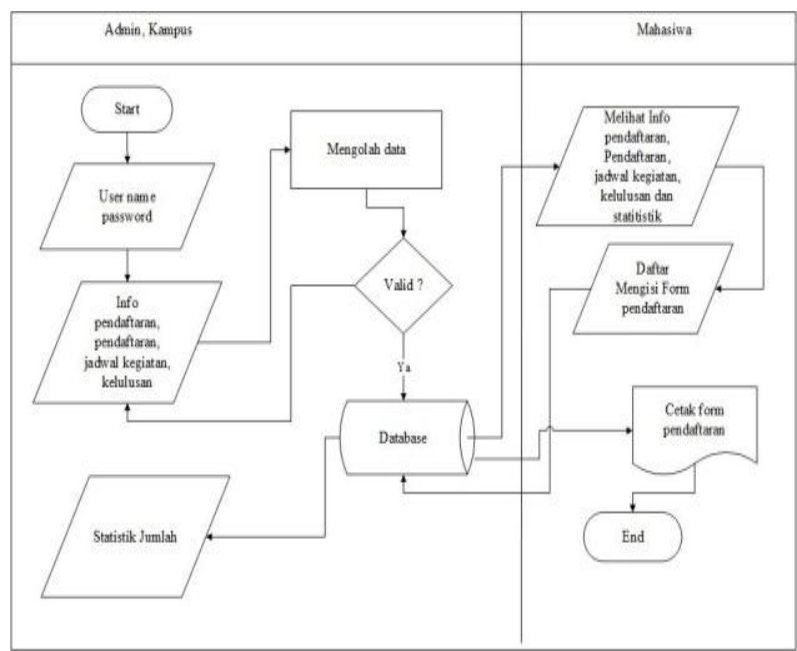

Gambar 3. Flowchart Sistem Yang

Diusulkan

\section{PERANCANGAN SISTEM}

\section{Perancangan Tabel Database}

Tabel 1. Tbl_informasi

\begin{tabular}{|c|l|l|c|c|}
\hline No & Field & Type & Lenght & Primary Key \\
\hline 1 & Id & Integer & 3 & $*$ \\
\hline 2 & Nama_info & Varchar & 50 & \\
\hline 3 & Isi_info & Text & & \\
\hline 4 & Tanggal & Date & & \\
\hline 5 & Dibaca & Integer & 3 & \\
\hline 6 & Status & Integer & 1 & \\
\hline
\end{tabular}

Tabel 2. Tbl_Jurusan

\begin{tabular}{|c|c|c|c|c|}
\hline No & Field & Type & Lenght & Primary Key \\
\hline 1 & Id_jurusan & Integer & 2 & $*$ \\
\hline 2 & Nama & Varchar & 35 & \\
\hline
\end{tabular}

Tabel 3.Tbl_login

\begin{tabular}{|c|l|c|c|c|}
\hline No & \multicolumn{1}{|c|}{ Field } & Type & Lenght & Primary Key \\
\hline 1 & Id_login & Integer & 11 & $*$ \\
\hline 2 & Nama & Varchar & 50 & \\
\hline 3 & Username & Varchar & 50 & \\
\hline 4 & Password & Text & & \\
\hline 5 & Status & Integer & 1 & \\
\hline
\end{tabular}

Tabel 4.Tbl_detail kegiatan

\begin{tabular}{|c|l|c|c|c|}
\hline No & \multicolumn{1}{|c|}{ Field } & Type & Length & Primary Key \\
\hline 1 & Id_detail & Integer & 4 & $*$ \\
\hline 2 & Id_kegiatan & Integer & 3 & \\
\hline 3 & Pendaftaran & Varchar & 100 & \\
\hline 4 & Tes_tulis & Varchar & 510 & \\
\hline 5 & Tes_wawancara & Varchar & 100 & \\
\hline 6 & He_registrasi & Varchar & 100 & \\
\hline 7 & Kuliah_umum & Varchar & 100 & \\
\hline
\end{tabular}

Tabel 5.Tbl_kelulusan

\begin{tabular}{|c|l|l|c|c|}
\hline No & Field & Type & Lenght & Primary Key \\
\hline 1 & Kode_pendaftaran & Varchar & 7 & $*$ \\
\hline 2 & Nik & Varchar & 10 & \\
\hline 3 & Status & Integer & 1 & \\
\hline
\end{tabular}

Tabel 6.Tbl_pendaftaran

\begin{tabular}{|c|l|c|c|c|}
\hline No & \multicolumn{1}{|c|}{ Field } & Type & Lenght & Primary Key \\
\hline 1 & Nik & Varchar & 10 & $*$ \\
\hline 2 & Nama & Varchar & 35 & \\
\hline 3 & Ttl & Varchar & 50 & \\
\hline 4 & Jk & Char & 1 & \\
\hline 5 & Agama & Integer & 1 & \\
\hline 6 & Wn & Varchar & 50 & \\
\hline 7 & Alamat & Text & & \\
\hline 8 & Nama_ibu & Varchar & 25 & \\
\hline 9 & Jenjang_pddk & Integer & 1 & \\
\hline 10 & Asal_sekolah & Varchar & 50 & \\
\hline 11 & Nem & Varchar & 7 & \\
\hline 12 & Jenjang_jrs & Integer & 1 & \\
\hline 13 & Pilihan & Varchar & 5 & \\
\hline 14 & Info & Integer & 1 & \\
\hline
\end{tabular}

Tabel 7.Tbl_statistik

\begin{tabular}{|c|l|c|c|c|}
\hline No & \multicolumn{1}{|c|}{ Field } & Type & Lenght & Primary Key \\
\hline 1 & Id & Integer & 2 & $*$ \\
\hline 2 & Id_jurusan & Integer & 2 & \\
\hline 3 & Jumlah & Integer & 3 & \\
\hline
\end{tabular}

\section{IMPLEMENTASI SISTEM}

Implementasi merupakan tahapan peletakan sistem yang sudah dibuat berbdasarkan analisis, perancangan serta codingan ke dalam bahasa pemrograman, 
berikut merupakan meruapakan beberapa hasil implementasi sistem pada politeknik sains dan teknologi wiratatama maluku utara

\section{Menu Home}

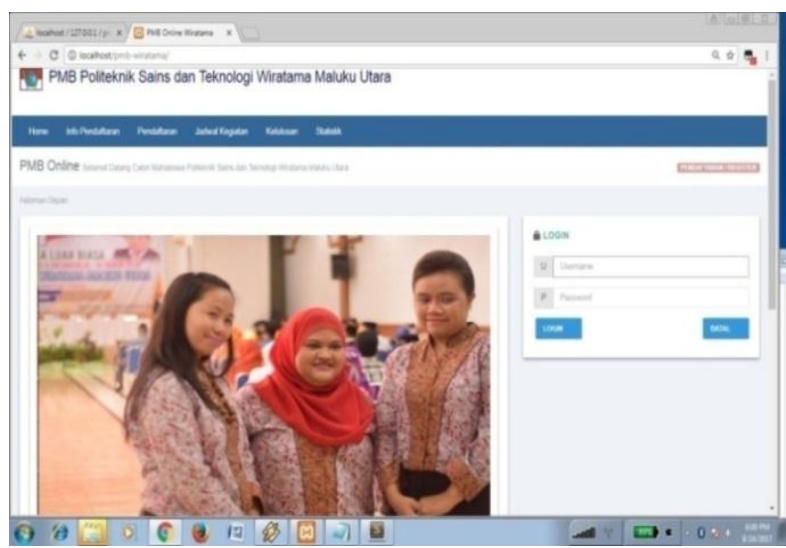

Gambar 4.Tampilan Menu Home

\section{Halaman Menu Admin}

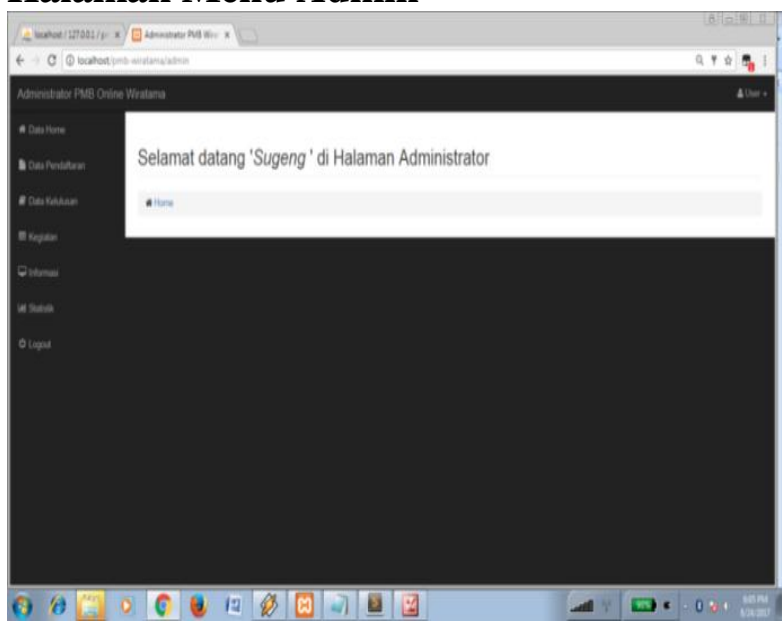

Gambar 5.Menu Admin

\section{Halaman Menu Informasi Pendaftaran}

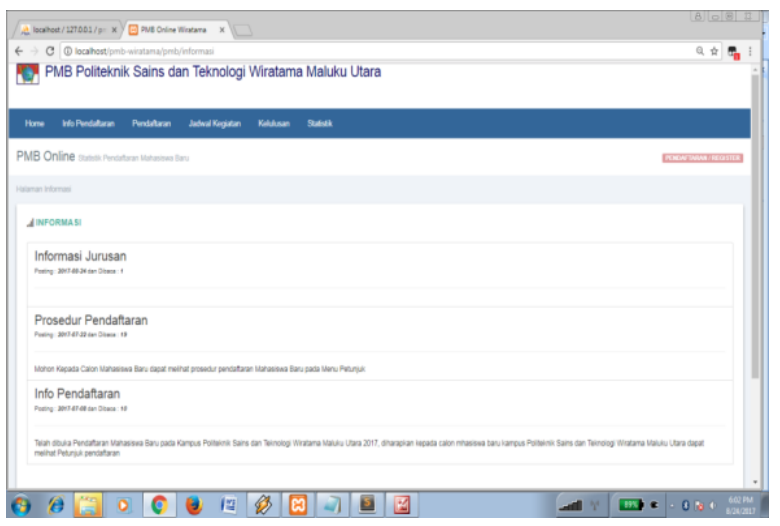

Gambar 6. Menu Informasi Pendaftaran

\section{Halaman Menu Pendaftaran}

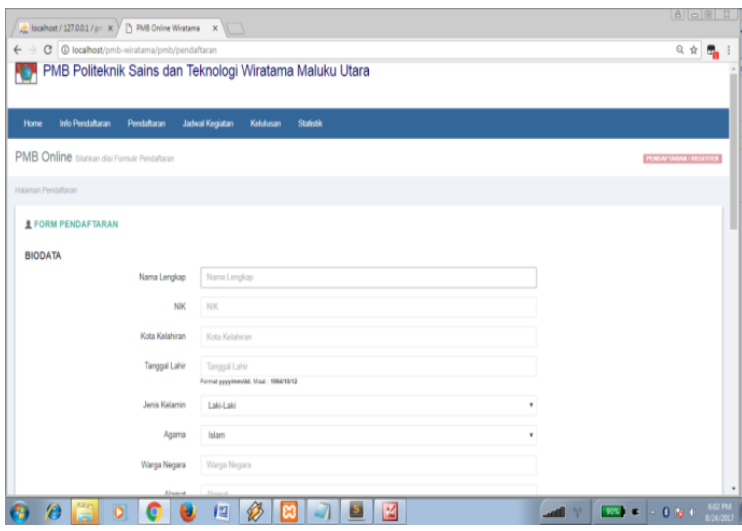

Gambar 7. Menu Pendaftaran

\section{Halaman Menu Pendaftaran Berhasil}

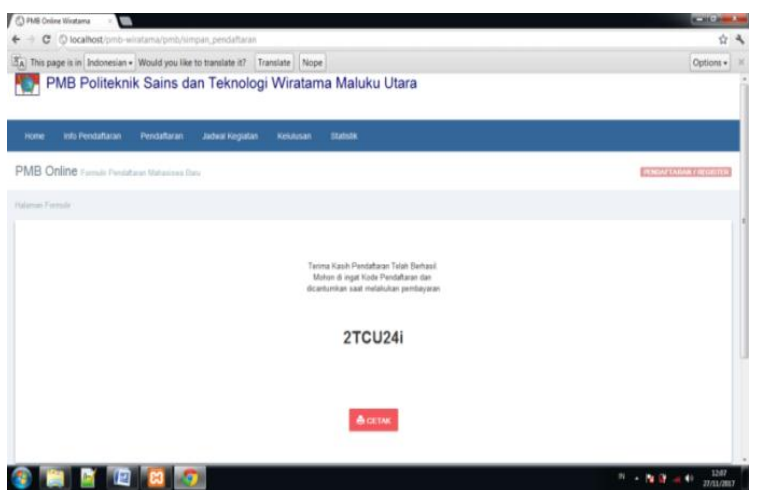

Gambar 8. Menu Pendaftaran berhasil

\section{Halaman Menu Cek Kelulusan}

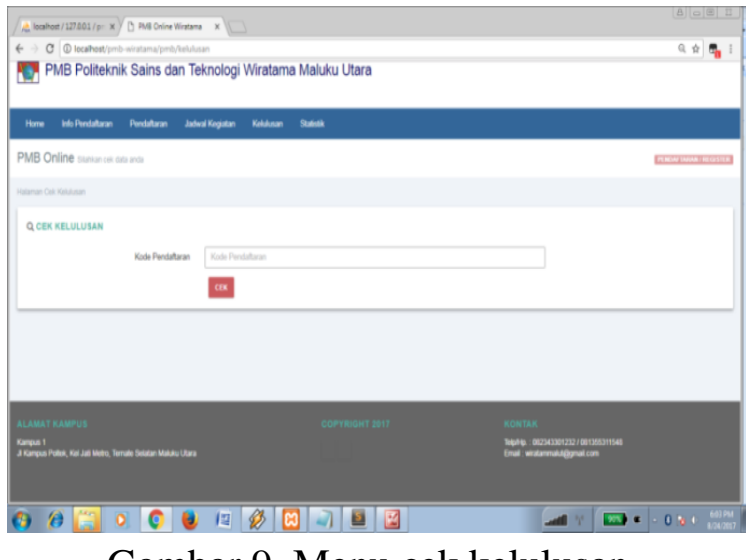

Gambar 9. Menu cek kelulusan

\section{Pengujian Sistem Blackbox}

Pengujian sistem blackbox merupakan pengujian sistem yang menguji cara kerja berdasarkan fungsi-fungsi menu yang dijalankan pada sistem, secara tidak lansung bahwa sistemyang dijalankan tidak eror atau tidak mengalami kegagalan 
saat sistem dijalankan, berikut merupakan hasil dari beberapa pengujian blackbox pada sistem pendaftaran mahasiswa baru berbasis web pada politeknik sains dan teknologi wiratama maluku utara

\section{Pengujian admin}

Tabel 8. Pengujian Admin

\begin{tabular}{|c|c|c|c|c|}
\hline No & Rancangan Proses & Hasil & Keterangan & Jenis Pengujian \\
\hline 1 & Info Pendaftaran & ok & info pendaftaran & Black Box \\
\hline
\end{tabular}

Tabel 9. Pengujian Pendaftaran

\begin{tabular}{|c|l|c|c|c|}
\hline No & \multicolumn{1}{|c|}{ Rancangan Proses } & Hasil & Keterangan & Jenis Pengujian \\
\hline 1 & Nama Lengkap & ok & Input Benar & Black Box \\
\hline 2 & NIK & ok & Input Benar & Black Box \\
\hline 3 & Kota Kelahiran & ok & Input Benar & Black Box \\
\hline 4 & Tanggal Lahir & ok & Input Benar & Black Box \\
\hline 5 & Jenis Kelamin & ok & Input Benar & Black Box \\
\hline 6 & Agama & ok & Input Benar & Black Box \\
\hline 7 & Warga Negara & ok & Input Benar & Black Box \\
\hline 8 & Alamat & ok & Input Benar & Black Box \\
\hline 9 & RT/RW & ok & Input Benar & Black Box \\
\hline 10 & Kelurahan & ok & Input Benar & Black Box \\
\hline 11 & Kecamatan & ok & Input Benar & Black Box \\
\hline 12 & Provinsi & ok & Input Benar & Black Box \\
\hline 13 & Kabupaten & ok & Input Benar & Black Box \\
\hline 14 & Kode Pos & ok & Input Benar & Black Box \\
\hline 14 & Nama Ibu & ok & Input Benar & Black Box \\
\hline 16 & Jenjang Pendidikan & ok & Input Benar & Black Box \\
\hline 17 & Sekolah Asal & ok & Input Benar & Black Box \\
\hline 18 & Nilai Rata-Rata/ NEM & ok & Input Benar & Black Box \\
\hline 19 & Jenjang Pendidikan & ok & Input Benar & Black Box \\
\hline 20 & Pilihan 1 & ok & Input Benar & Black Box \\
\hline 21 & Pilihan 2 & Input Benar & Black Box \\
\hline 22 & Pilihan 3 & Input Benar & Black Box \\
\hline 23 & Info Pendaftaran dari & Input Benar & Black Box \\
\hline 24 & Security & Input Benar & Black Box \\
\hline 25 & Register & & \\
\hline
\end{tabular}

Tabel 9. Pengujian Cek Kelulusan

\begin{tabular}{|c|c|c|c|c|}
\hline$N_{0}$ & Rancangan Proses & Hasil & Keterangan & Jenis Pengujan \\
\hline 1 & Jadwal Kegiatan & ok & Informasi Jadwal kegiatan & Black Box \\
\hline
\end{tabular}

Tabel 10. Pengujian Statistik

\begin{tabular}{|c|l|c|c|c|}
\hline No & Rancangan Proses & Hasil & Keterangan & Jenis Pengujan \\
\hline 1 & Statistik & ok & Sesuai data & Black Box \\
\hline
\end{tabular}

KESIMPULAN
Berdasarkan implementasi dan pengujian sistem dengan judul Sistem Informasi Pendaftaran Mahasiswa Baru Pada Politeknik Sains \& Teknologi Wiratama Maluku Utara bebasis Web maka dapat disimpulkan sebagai berikut: 1). Sistem informasi pendaftaran mahasiswa baru berbasis website dapat mempermudah admin dalam pengolahan dan pengelolaan data calon mahasiswa baru. Serta dapat mempercepat informasi pendaftaran dan pengumuman hasil calon mahasiswa baru melalui website. 2). Aplikasi sistem informasi pendaftaran calon mahasiswa baru berbasis website dapat membantu panitia dalam penyeleksian calon mahasiswa baru untuk hal-hal yang berkaitan dengan pengaksesan data dan pemroses data,juga untuk meningkatkan kinerja dan pelayanan pada Politeknik Sains \& Teknologi Wiratama Maluku Utara lebih efektif dan efisien.

Saran dari peneliti untuk pengembangan lebih lanjut dari hasil ini adalah sebagai berikut: 1). Diharapkan Sistem Informasi Pendaftaran Mahasiswa Baru Pada Politeknik Sains \& Teknologi wiratama Maluku Utara Berbasis Web ini dapat diterapkan untuk menggantikan dengan sistem yang lama. 2). untuk mengembangkan sistem ini dengan menambahkan seleksi ujian dan pembayaran secara online

\section{DAFTAR PUSTAKA}

Fathansyah. 2004. Basis Data. Bandung, Penerbit Informatika Bandung

Bin Ladjamudin, Al Bahra. 2005. Analisis

Dan Desain Sistem Informasi.

Tangerang:Graha Ilmu.

Jogiyanto, H. M, 2005. Analisa dan Desain.Yogyakarta : Penerbit Andi Offset. 
Sutarman 2007, Membangun Aplikasi Web Dengan PHP dan MySQL, GRAHA ILMU, Yogyakarta

Nugroho, B. 2008. Latihan Membuat Aplikasi Web PHP dan MySQL dengan Dreamweaver. Yogyakarta: Gava Media.

Komputer, W. 2010. Tuntunan Praktis Belajar Database Menggunakan MySQL. Yogyakarta: Andi Offset.

Saputra, A. 2011. Trik dan Solusi Jitu Pemrograman PHP. Jakarta: PT. Elex Media Komputindo.

Sugiyono. 2011. Metode Penelitian Kuantitatif, Kualitatif dan $R \& D$. Jakarta: Alfabeta

Darmawan, D dan Fauzi, Nur. 2013. Sistem Informasi Manajemen. Bandung: PTRemaja Rosdakarya Bandung.

Kadir, Abdul. 2013. Pengenalan Sistem Informasi Edisi Revisi. Yogyakarta: Andi Offset.

Kadir, Abdul dan Triwahyuni. 2013. Pengantar Teknologi Informasi Edisi Revisi. Yogyakarta, Penerbit Andi Offset.

S, Rosa A. Dan M. Shalahuddin. 2013. Rekayasa Perangkat Lunak. Bandung: Informatika.

Taufiq, Rohmat. 2013. Sistem Informasi Manajemen (Konsep Dasar, Analisis dan Metode Pengembangan).

Muharto \& Ambarita, A. 2016. Metode Penelitian Sistem Informasi: Mengatasi Kesulitan Mahasiswa Dalam Menyusun Proposal Penelitian. Deepublish. Yogyakarta.

Wijaya, A ( 2007 ) Penggunaan DFD dan ERD pada analisis dan perancang sistem informasi penjualan suku cadang dan pelayanan service pada PT. Mitra Maju Mobilindo, Jurnal Teknik Industri : media keilmuan dan kaitan aplikasi bidang teknik industri

Arisandy Ambarita, Sendiwati Haming, Perancangan Sistem Informasi Administrasi Siswa Kursus Berbasis Web pada Lembaga Kursus dan Pelatihan Bina Ilmu Ternate, SAINTEK - Jurnal Sains dan Teknologi, Volume 5 Nomor 2 November 2014, ISSN 2088-5911

Rusli Muhidin, N Faisal Kharie, Muin Kubais, Analisis dan Perancangan Sistem Informasi Pada SMA Negeri 18 Halmahera Selatan Sebagai Media Promosi Berbasis Web, IJISIndonesian Journal On Information System, Volume 2 Nomor 2, September 2017, ISSN 2548-6438

Syahril Hasan, Sistem Informasi Pengisian Kartu Rencana Studi (KRS) Berbasis Web Pada Politeknik Sains Dan Teknologi Wiratama Maluku Utara, Indonesian Journal on Networking and Security, Volume 6 No 1 - 2017, ISSN : 2302-5700 (Print) - 23546654 (Online) 